\title{
Evidence of O-O Bond Formation in the Final Metastable S3 State of Nature's Water Oxidizing Complex Implying a Novel Mechanism of Water Oxidation
} DOI:

10.1021/acs.jpclett.8b02793

\section{Document Version \\ Accepted author manuscript}

Link to publication record in Manchester Research Explorer

Citation for published version (APA):

Corry, T. A., \& O'malley, P. J. (2018). Evidence of O-O Bond Formation in the Final Metastable $\mathrm{S}_{3}$ State of Nature's Water Oxidizing Complex Implying a Novel Mechanism of Water Oxidation. Journal of Physical Chemistry Letters, 9(21), 6269-6274. https://doi.org/10.1021/acs.jpclett.8b02793

\section{Published in:}

Journal of Physical Chemistry Letters

\section{Citing this paper}

Please note that where the full-text provided on Manchester Research Explorer is the Author Accepted Manuscript or Proof version this may differ from the final Published version. If citing, it is advised that you check and use the publisher's definitive version.

\section{General rights}

Copyright and moral rights for the publications made accessible in the Research Explorer are retained by the authors and/or other copyright owners and it is a condition of accessing publications that users recognise and abide by the legal requirements associated with these rights.

\section{Takedown policy}

If you believe that this document breaches copyright please refer to the University of Manchester's Takedown Procedures [http://man.ac.uk/04Y6Bo] or contact uml.scholarlycommunications@manchester.ac.uk providing relevant details, so we can investigate your claim.

\section{OPEN ACCESS}




\section{Evidence of O-O Bond Formation in the Final Metastable $\mathrm{S}_{3}$ State of Nature's Water Oxidising Complex Implies a Novel Mechanism of Water Oxidation}

Thomas A Corry and Patrick J O’Malley*,

School of Chemistry, The University of Manchester, Manchester, M13 9PL, UK.

E-mail: patrick.omalley@manchester.ac.uk

ABSTRACT: A novel mechanism for the final stages of Nature's photosynthetic water oxidation to molecular oxygen is proposed. This is based on a comparison of experimental and broken symmetry density functional theory (BS-DFT) calculated geometries and magnetic resonance properties of water oxidising complex models in the final metastable oxidation state, $S_{3}$. We show that peroxo models of the $S_{3}$ state are in vastly superior agreement with the current experimental structural determinations compared with oxohydroxo models. Comparison of experimental and BS-DFT calculated ${ }^{55} \mathrm{Mn}$ hyperfine couplings for the EPR visible form shows better agreement for the oxo-hydroxo model. An equilibrium between oxo-hydroxo and peroxo models is proposed for the $\mathrm{S}_{3}$ state and the major implications for the final steps in the water oxidation mechanism are analysed and discussed. 


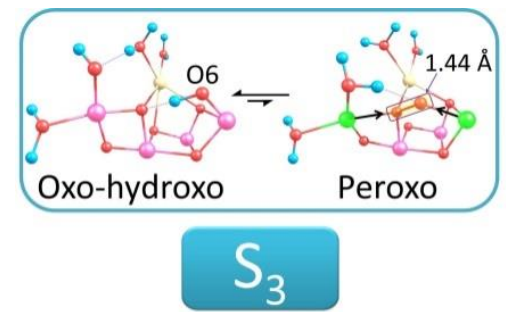

\section{TOC Graphic}

Nature's invention of a molecular device to dissociate water into molecular oxygen and metabolically bound hydrogen by using visible light as the source of Gibbs energy was the key stage in the development of all oxygenic photosynthetic organisms in the early biosphere. ${ }^{1}$ The catalytically active water oxidising complex (WOC) located in Photosystem II, is a $\mathrm{Mn}_{4} \mathrm{O}_{5 / 6} \mathrm{CaW}_{4}$ cluster shown in Figure 1. To produce molecular oxygen from two water molecules, Kok proposed that the WOC active site undergoes four oneelectron oxidation steps, giving rise to five distinct progressively oxidizing storage states designated $S_{n}$, where $n=0-4$, represents the number of one-electron oxidations stored, before releasing $\mathrm{O}_{2}$ during the rapid decay of $\mathrm{S}_{4} \rightarrow \mathrm{S}_{0}{ }^{2,3}$ The final metastable state that can be detected and characterised experimentally is the $S_{3}$ state. The exact structural and electronic characterisation of this state is crucial to a full understanding of the water oxidation reaction. This goal was greatly enhanced by the recent report of an atomic-level X-ray crystal structure of the WOC using X-ray free electron lasers (XFEL), after two light flashes (2F) and poised predominantly in the $S_{3}$ state. ${ }^{4,5}$ Previously high resolution electron paramagnetic resonance (EPR) spectroscopy of an EPR active, $S=3$ state population, had been used to propose that all four $\mathrm{Mn}$ ions are present in the IV oxidation state and octahedrally coordinated. ${ }^{6}$ This was facilitated by the addition of an extra hydroxo ligand $\mathrm{O} 6$ to the $\mathrm{Mn}_{1}$ ion, on $\mathrm{S}_{3}$ formation, leading to an oxo (O5) - hydroxo (O6) interaction apparently poised for O-O bond formation in the $\mathrm{S}_{4}$ state. $^{7}$ While the $2 \mathrm{~F}$ X-ray crystal structure revealed by Suga et $\mathrm{al}^{4}$ does indicate an additional oxygen atom (O6) coordinating to the $\mathrm{Mn}_{1}$ ion, the O5-O6, $\mathrm{Mn}_{1}$-O6 and $\mathrm{Mn}_{4^{-}}$ 
O5 bond lengths were recently shown to be best modelled by a bridging peroxo with $\mathrm{Mn}_{1}$ and $\mathrm{Mn}_{4}$ present as Mn (III) ions. ${ }^{8}$ This additional O6 was not resolved in the $2 \mathrm{~F}$ crystal structure presented earlier by Young et $\mathrm{al}^{5}$ most likely due to the poorer resolution in that determination as explained previously by Suga et $\mathrm{al}^{4}$, Kato et $\mathrm{al}^{9}$ and Wang et al. ${ }^{10}$ In this communication we use broken symmetry density functional theory (BS-DFT) calculations on large models of the WOC to further investigate these possibilities. We calculate the structural and magnetic properties for both oxo-hydroxo and peroxo models generated directly from the $\mathrm{S}_{3}$ state crystal structure coordinates and compare these with the experimental determinations. We show that the peroxo models are in vastly superior agreement with the experimental structural determinations compared with oxo-hydroxo models. Comparison of experimental and BS-DFT calculated ${ }^{55} \mathrm{Mn}$ hyperfine couplings (hfcs) shows somewhat better agreement for the oxo-hydroxo model. Both the likelihood of the $S_{3}$ state corresponding to an equilibrium between oxo-hydroxo and peroxo forms and novel implications for the final steps in water oxidation are discussed.

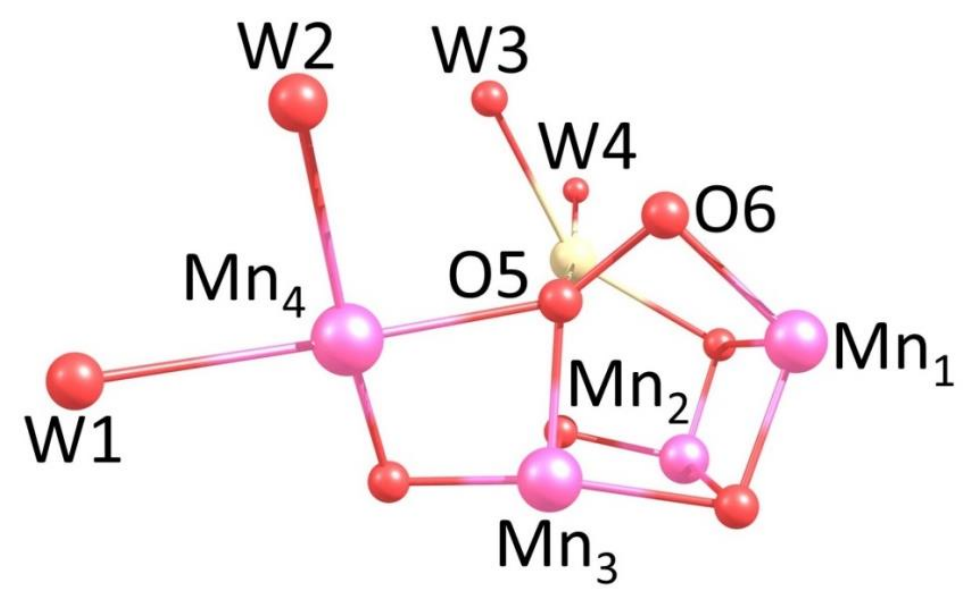

Figure 1: Double flashed (2F) structure of the WOC core (PDB file 5WS6), with numbering scheme used throughout this report for the cluster models. The colour code used is: $\mathrm{Mn}$ (pink), calcium (white) and oxygen (red).

As starting coordinates, large models of the Suga et al. ${ }^{4}$ crystal structure determination (PDB: 5WS6 Chain A) were optimised either as oxo-hydroxo or peroxo forms and all models located are shown in Figure 2. For oxo-hydroxo models only O6 protonated forms 
were found to represent stationary points on the potential energy surface and these differed by the presence (oxo-hydroxo-A) or absence (oxo-hydroxo-B) of hydrogen bond donation to O5. In both oxo-hydroxo models, W2 is represented as an hydroxo ligand, as strong evidence has been presented for this protonation state in the prior $S_{2}$ state. ${ }^{11,12}$ Three peroxo models were examined depending on the protonation and hydrogen bond interaction of W2. In peroxo-A, W2 is a fully protonated water with hydrogen bond donation to O5 and O6 while in peroxo-B, fully protonated W2 does not hydrogen bond to either O5 or O6. As stated both have fully protonated W2 in their optimised forms as starting initially with either O5 or O6 protonated gave rise on optimisation to transfer of the proton to the W2 hydroxo, generating peroxo-A. In addition, for comparison, we used another model peroxo-C in which W2 is an hydroxo ligand and O5 and O6 are both deprotonated. 


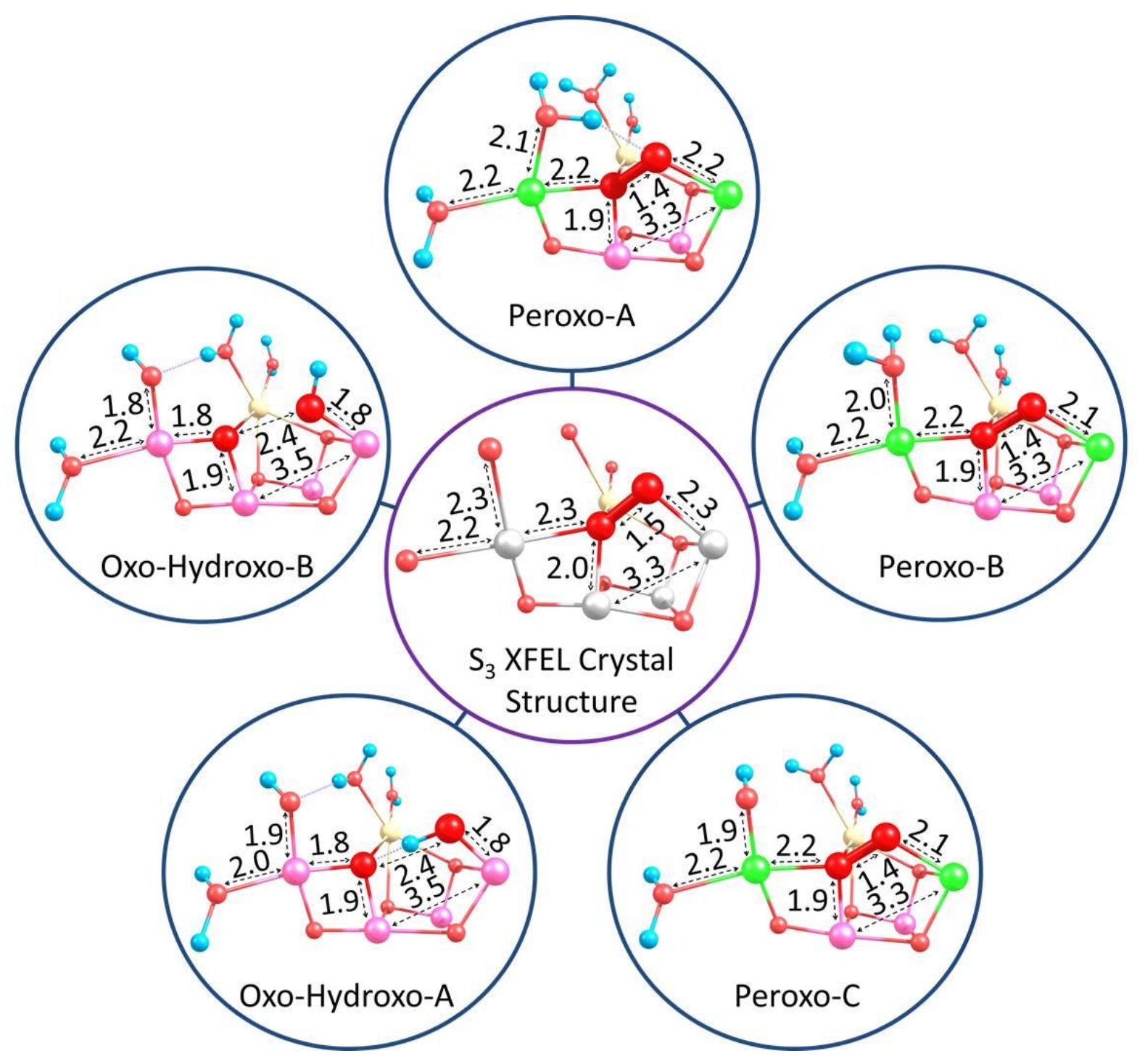

Figure 2: Peroxo and oxo-hydroxo models geometry optimised from X-ray crystal structure coordinates of PDB:5WS6 (Chain A) with relevant optimised bond lengths shown for comparison. The colour code used for models is: Mn(IV) [pink], Mn(III) [green], Mn(unassigned oxidation state) [silver], calcium [white], hydrogen [blue] and oxygen [red]. Oxygen bond forming $\mathrm{O} 5$ and $\mathrm{O} 6$ highlighted in red.

The structure and some key optimised interatomic distances calculated for all models are shown in Figure 2 and compared with the X-ray determined structure. Overlays of the crystal structure coordinates and the optimised models are also shown in Figure S3 along with a more extensive comparison, Table S2, of interatomic distances. It is clear that all peroxo models are in vastly superior agreement with the experimentally determined structure compared with the two oxo-hydroxo models and indeed it can be stated categorically that only a peroxo model is compatible with the current X-Ray structure determination of Suga et 
al. ${ }^{4}$ Comparison with extended X-ray absorption fine structure (EXAFS) data in Table S2, shows similar agreement for both types of model. For the peroxo models, Mulliken spin population analysis, Table $\mathrm{S} 4$ shows that $\mathrm{Mn}_{1}$ and $\mathrm{Mn}_{4}$ are in oxidation state III (spin populations near 4.0 respectively) while $\mathrm{Mn}_{3}$ and $\mathrm{Mn}_{2}$ are present in the IV oxidation state (spin populations near 3.0). This explains the relatively long $\mathrm{Mn}_{1}-\mathrm{O} 6$ and $\mathrm{Mn}_{4}-\mathrm{O} 5$ bond lengths which lie along the Jahn-Teller axes of these ions. The $\mathrm{Mn}_{3}-\mathrm{O} 5$ bond length is somewhat shorter for all peroxo models due to the absence of Jahn-Teller distortion and again agrees with the X-ray structure determination. It would appear that $\mathrm{Mn}_{3}$ is the ion which anchors the peroxo in the WOC structure. The peroxo ligand is therefore bound asymmetrically in the complex with its $\mathrm{O} 5$ terminus bonded to both $\mathrm{Mn}_{4}$ and $\mathrm{Mn}_{3}$ and its $\mathrm{O} 6$ terminus bonded to $\mathrm{Mn}_{1}$. $\mathrm{O} 5$ and $\mathrm{O} 6$ to a lesser extent are additionally ligated to $\mathrm{Ca}$. PeroxoA, where W2 acts as a donor to both $\mathrm{O} 5$ and $\mathrm{O} 6$, has a noticeably narrower $\mathrm{W} 4 \mathrm{Mn}_{4} \mathrm{O} 5$ bond angle of $77.6^{\circ}$ compared with $89.9^{\circ}$ for peroxo-B. Peroxo-A may represent an intermediate between oxo-hydroxo and peroxo-B where the O6 proton is transferred from O6 to the W2 hydroxo in the process of $\mathrm{O}-\mathrm{O}$ bond formation between $\mathrm{O} 5$ and $\mathrm{O} 6$, see below.

EPR studies have identified two populations of $S_{3}$. The first is an EPR detectable form identified as arising predominantly from an $\mathrm{S}=3$ ground state. ${ }^{13,14}$ The second has been shown, on near infrared (NIR) illumination at cryogenic temperatures, to give rise to a distinct EPR resonance, a so-called split signal assumed to arise due to induced oxidation of $\mathrm{Y}_{\mathrm{Z}}$ by the photoactivated WOC. ${ }^{15,16}$ The first $\mathrm{S}=3$ population has been further studied by Eldor Detected Nuclear Magnetic Resonance (EDNMR) which measured the ${ }^{55} \mathrm{Mn}$ hfcs for the four Mn ions present. These have been interpreted as indicating that all $\mathrm{Mn}$ ions are present in the IV oxidation, octahedrally coordinated and composed of a pair of two large and two small magnitude hfcs. ${ }^{6}$ 
It has been demonstrated that exchange coupling constants $J i j$, the ground spin state and the projected ${ }^{55} \mathrm{Mn}$ hfcs can be reliably calculated by using BS-DFT calculated exchange couplings constants in the diagonalization of the isotropic Heisenberg Van Vleck Hamiltonian. ${ }^{7,17}$ The results of such an analysis is given in Table 1 which shows the calculated ground state spin and the projected isotropic and anisotropic ${ }^{55} \mathrm{Mn}$ hfcs for all models studied. The calculated values for the oxo-hydroxo models are similar to those calculated previously for "open-cubane" models generated from the dark adapted crystal structure. ${ }^{6,8,7}$ As all ions are $\mathrm{Mn}(\mathrm{IV})$, low anisotropy is exhibited throughout and grouping of the couplings into a high magnitude and low magnitude pairs, as found experimentally, is apparent especially for oxo-hydroxo-B. We note however that the magnitudes of the smaller pair are significantly larger than the experimentally reported values. These smaller hfcs are probably the least accurately determined in the experimental report and have also been found to be highly sensitive to small variations in the $\mathbf{J}_{34}$ exchange coupling value. ${ }^{7,8}$ Peroxo-A, and peroxo-B have calculated hfcs which are similar in magnitude for all four $\mathrm{Mn}$ ions in disagreement with the experimental determination. Peroxo-C does display calculated values which fall into two sets of large and small magnitude values but a ground state of $S_{\mathrm{GS}}=4$ is calculated for this model using the exchange coupling analysis. In general it would appear that the oxo-hydroxo models better reproduce some of the experimentally determined values while the peroxo models show poorer agreement. So, based on the comparison with the structure determination of Suga et al ${ }^{4}$, the $\mathrm{S}_{3}$ state is best described as a peroxo model. On the other hand, comparison of calculated and experimental ${ }^{55} \mathrm{Mn}$ hfcs would, with certain caveats, favour an oxo-hydroxo model for the $S=3$ species detected by EPR. As mentioned in the introduction, another separate population, $30-40 \%$, of $S_{3}$ exists ${ }^{15,16}$ which is only EPR detectable on NIR illumination at cryogenic temperatures. This has been found to be in 
Table 1: BS-DFT calculated ground spin state and projected ${ }^{55} \mathrm{Mn}$ isotropic $\left(\mathrm{A}_{\mathrm{iso}}\right)$ and $\mathrm{T}_{\mathrm{i}} \mathrm{hfcs}$ constants (in $\mathrm{MHz}$ ) for all models studied compared to experimental determinations.

\begin{tabular}{|c|c|c|c|c|c|}
\hline Model & & $\mathrm{A}_{\text {iso }}$ & $\mathrm{T}_{1}$ & $\mathrm{~T}_{2}$ & $\mathrm{~T}_{3}$ \\
\hline \multirow{4}{*}{$\begin{array}{c}\text { Peroxo-A } \\
\mathbf{S}_{\mathrm{GS}}=\mathbf{3}\end{array}$} & $\mathrm{Mn}_{4}$ & -130 & -26 & -8 & 34 \\
\hline & $\mathrm{Mn}_{3}$ & -72 & -3 & 1 & 3 \\
\hline & $\mathrm{Mn}_{2}$ & -68 & -3 & 1 & 3 \\
\hline & $\mathrm{Mn}_{1}$ & 83 & -24 & 10 & 14 \\
\hline \multirow{4}{*}{$\begin{array}{c}\text { Peroxo-B } \\
S_{\mathrm{GS}}=4\end{array}$} & $\mathrm{Mn}_{4}$ & -128 & -28 & -6 & 34 \\
\hline & $\mathrm{Mn}_{3}$ & -109 & -10 & -1 & 12 \\
\hline & $\mathrm{Mn}_{2}$ & -58 & 2 & -1 & -1 \\
\hline & $\mathrm{Mn}_{1}$ & 85 & 14 & 8 & -22 \\
\hline \multirow{4}{*}{$\begin{array}{c}\text { Peroxo-C } \\
S_{G S}=4\end{array}$} & $\mathrm{Mn}_{4}$ & -103 & -24 & 1 & 23 \\
\hline & $\mathrm{Mn}_{3}$ & -83 & -7 & -1 & 7 \\
\hline & $\mathrm{Mn}_{2}$ & 22 & -1 & 0 & 1 \\
\hline & $\mathrm{Mn}_{1}$ & -45 & -7 & -5 & 12 \\
\hline \multirow{4}{*}{$\begin{array}{c}\text { Oxo-hydroxo- } \\
\text { A } \\
\mathbf{S}_{\mathrm{GS}}=3\end{array}$} & $\mathrm{Mn}_{4}$ & 40 & -1 & 0 & 1 \\
\hline & $\mathrm{Mn}_{3}$ & -39 & -3 & 0 & 3 \\
\hline & $\mathrm{Mn}_{2}$ & -76 & -5 & 1 & 4 \\
\hline & $\mathrm{Mn}_{1}$ & -84 & -5 & -1 & 6 \\
\hline \multirow{4}{*}{$\begin{array}{c}\text { Oxo-hydroxo- } \\
\text { B } \\
S_{\mathrm{GS}}=3\end{array}$} & $\mathrm{Mn}_{4}$ & 18 & -1 & 0 & 1 \\
\hline & $\mathrm{Mn}_{3}$ & -19 & -1 & 0 & 1 \\
\hline & $\mathrm{Mn}_{2}$ & -80 & -5 & 1 & 4 \\
\hline & $\mathrm{Mn}_{1}$ & -83 & -5 & 1 & 4 \\
\hline \multirow{4}{*}{$\begin{array}{c}\operatorname{Exp}^{6} \\
S_{\mathrm{GS}}=3\end{array}$} & $\mathrm{~A}_{1}$ & -99.0 & -1.2 & -1.2 & 2.4 \\
\hline & $\mathrm{A}_{2}$ & -95.6 & -3.8 & 1.8 & 1.8 \\
\hline & $\mathrm{A}_{3}$ & -25.9 or +7.0 & - & - & - \\
\hline & $\mathrm{A}_{4}$ & $0.5(\leq 5)$ & - & - & - \\
\hline
\end{tabular}


equilibrium with the $S=3$ form $^{15}$. Importantly this is distinct from the $S=3$ form $^{15}$ and not its precursor as has been suggested by Retegan et al. ${ }^{18}$

It is generally believed that photoactivation of the WOC by NIR requires the presence of Mn (III) ${ }^{19,20}$ so a potential candidate for this is the peroxo form. The combination of integer spin ( $\mathrm{S}=3$ or 4) and large zero field splitting magnitude (due to $\mathrm{Mn}(\mathrm{III})$ ) for this component would also explain its lack of detection by EPR. ${ }^{21}$ NIR activation with expected reduction would lead to a half-integer spin (Kramers doublet) system more readily detected by EPR. ${ }^{21}$ Supported by the presence of two distinct populations for $S_{3}$ measured by EPR, we propose that in $\mathrm{S}_{3}$ an equilibrium exists between oxo-hydroxo and peroxo with the experimental conditions detecting/favouring one
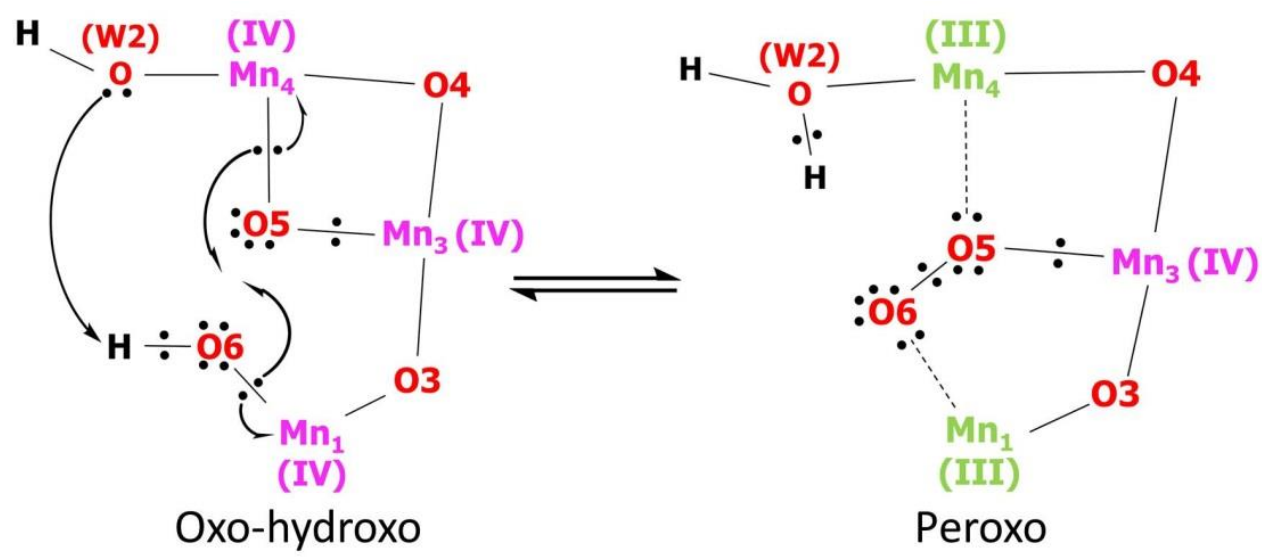

Scheme 1. Schematic representation of oxo-hydroxo/peroxo equilibrium described in text, highlighting the electron movements involved.

form over the other, Scheme 1 and Figure 3. As demonstrated in Scheme 1 this equilibrium can be envisioned as a redox coupling mechanism involving concerted one-electron movements. This is similar to the equilibrium known for peroxo/oxo conversion in highcapacity layered-oxide electrodes ${ }^{22}$ and indeed has been previously speculated as arising in 
the $S_{3}$ state by Renger. ${ }^{23,1}$ based on kinetic analysis of the $S$ state transitions. Isobe at $\mathrm{al}^{24}$ have also suggsted that $S_{3}$ exists as an equilibrium of structures including oxo-hydroxo, peroxo, superoxo and oxyl radical species based on broken symmetry density functional states calculated using models based on the $S_{1}$ crystal structure coordinates. Pushkar et al ${ }^{25}$ have recently combined crystallographic, spectroscopic and DFT results to illustrate the possibility of low barrier $\mathrm{O}-\mathrm{O}$ bond formation prior to $\mathrm{S}_{4}$. For the equilibrium model proposed here the relative populations are likely to be dependent on sample preparation and temperature. Based on the $1.5 \AA$ bond length observed in the crystal structure reported by Suga et $\mathrm{al}^{4}$, the predominant species present in that study would appear to be the peroxo form. ${ }^{8}$ For a more mixed state an intermediate $05-06$ bond length between oxo-hydroxo and peroxo might be expected. In this respect the accuracy limitations of the current crystal structures must be borne in mind and further more highly resolved crystal structure determinations are desirable. ${ }^{26}$ As has been previously found by Isobe et al ${ }^{24}$ energetic comparisons between the different oxo-hydroxo and peroxo models are notoriously dependent on the percentage of Hartree-Fock (HF) exchange used with low HF exchange levels favouring the oxo-hydroxo form and high HF exchange levels favouring the peroxo forms. Our own energetic comparisons are given in Table S5 which clearly demonstrates this effect as well. A calculation beyond density functional theory methods may clarify this but are for the foreseeable future infeasible for models of the size used here. A similar equilibrium between oxo and bridged peroxo has been shown to exist for bridged copper oxygen complexes. ${ }^{27,28}$ The experimentally verified copper oxo and peroxo equilibrium importantly demonstrates the feasibility of O-O bond formation arising soley through such an equilibrium without the need for generation of $\mathrm{Mn}(\mathrm{V})$ or oxyl radicals. In this respect we find that starting with a protonated $\mathrm{O} 5$ or $\mathrm{O} 6$ leads to transfer of this proton to the $\mathrm{W} 2 \mathrm{OH}$ group on optimisation of the peroxo model. Peroxo-A could be interpreted as an intermediate in 
this proton transfer process which accompanies oxo-hydroxo conversion to peroxo, Scheme 1. X-ray absorption and emission spectroscopy have been interpreted to show a significantly smaller average $\mathrm{Mn}$ oxidation change on $\mathrm{S}_{2}$ to $\mathrm{S}_{3}$ advancement ${ }^{29,30}$ compared with the previous S-state transitions. This has been attributed to absence of Mn oxidation in the $\mathrm{S}_{2}$ to $\mathrm{S}_{3}$ transition. ${ }^{31,32}$ As discussed in Yano and Yachandra ${ }^{30}$ interpretations of such changes in terms of formal oxidation changes on the Mn ions may be too simplified for a covalent complex like the WOC. By contrast, the changes occurring on the $S_{2}$ to $S_{3}$ transition have been attributed to Mn oxidation accompanied by a coordination change. ${ }^{33,34,35}$ The smaller average oxidation change between $S_{2}$ and $S_{3}$ is also fully compatible with the equilibrium model proposed here assuming the oxo-hydroxo form is in excess. ${ }^{18} \mathrm{O} /{ }^{16} \mathrm{O}$ exchange rates for the different S-states which show both oxygens exchanging in the $S_{3}$ state have been interpreted as indicating that $\mathrm{O}-\mathrm{O}$ bond formation can be ruled out in this state. ${ }^{36}$ However, the actual mechanism via which oxygens exchange in the WOC is unknown and may even involve multiple S-states or be diffusion limited. The equilibrium suggested here could contribute to the fast exchange rate observed.

The mechanism of $\mathrm{O}-\mathrm{O}$ bond formation proposed here arising from an equilibrium established in the $S_{3}$ state, is quite distinct from the current two leading proposals in the literature i.e. nucleophilic attack ${ }^{37,38}$ and oxo-oxyl radical coupling ${ }^{39,40}$ which are proposed to both occur in the $\mathrm{S}_{4}$ state. The formation of the $\mathrm{O}-\mathrm{O}$ bond in the $\mathrm{S}_{3}$ state is quite appealing from a mechanistic and kinetics point of view as it establishes O-O bond formation before the final electron transfer out of the WOC to oxidised $\mathrm{Y}_{\mathrm{Z}}$. Babcock et al have shown that there is virtual kinetic coincidence between the rate of $\mathrm{O}_{2}$ evolution and $\mathrm{Y}_{\mathrm{Z}}{ }^{\mathrm{OX}}$ reduction in the final $\mathrm{S}_{3} \mathrm{Y}_{\mathrm{Z}}{ }^{\mathrm{OX}}$ to $\mathrm{S}_{4}$ step $\left(\mathrm{t}_{1 / 2} \sim 1 \mathrm{~ms}\right) .^{41}$ This instantaneous formation of oxygen on $\mathrm{Y}_{\mathrm{Z}}$ reduction is difficult to rationalise if the $\mathrm{O}-\mathrm{O}$ bond formation reaction is still required to take place. In addition oxidation of the oxo-hydroxo form would require oxidation of $\mathrm{Mn}(\mathrm{IV})$ to $\mathrm{Mn}(\mathrm{V})$ or 
$\mathrm{Mn}(\mathrm{IV})$ oxyl. The electrode potential for this couple in acidic aqueous solution ranges from +2.7 to $+4.7 \mathrm{~V}^{42}$ which is well above the electrode potential of $\mathrm{Y}_{\mathrm{Z}}{ }^{\mathrm{ox}} / \mathrm{Y}_{\mathrm{Z}}$ of $+1.1 \mathrm{~V} \cdot{ }^{35} \mathrm{~A}$ drastic site-induced reduction in the $\mathrm{Mn}(\mathrm{V}) / \mathrm{Mn}(\mathrm{IV})$ electrode potential would be required to facilitate $\mathrm{Mn}(\mathrm{IV})$ oxidation by $\mathrm{Y}_{\mathrm{Z}}^{\mathrm{OX}}$. This conclusion is supported by a recent $\mathrm{X}$-ray emission spectroscopy study by Jensen et al who found no evidence of Mn(IV) oxidation in this final step. ${ }^{43}$ By contrast if peroxo formation has already occurred, this final electron transfer to $\mathrm{Y}_{\mathrm{Z}}{ }^{\mathrm{ox}}$ is likely to result in exclusive oxidation of peroxo to superoxo, $\left[\mathrm{E}^{0}\left(\mathrm{O}_{2}^{-1} / \mathrm{H}_{2} \mathrm{O}_{2}\right)=\right.$ $+890 \mathrm{mV}]^{42,44}$ shifting the $\mathrm{S}_{3}$ equilibrium towards the peroxo. The resultant superoxo would be expected to be rapidly oxidised to triplet oxygen $\left[\mathrm{E}^{0}\left(\mathrm{O}_{2} / \mathrm{O}_{2}^{-1}=-180 \mathrm{mV}\right]^{44}\right.$ by $\mathrm{Mn}_{3}(\mathrm{IV})$, see Figure 3. This would explain the instantaneous appearance of oxygen on $\mathrm{Y}_{\mathrm{Z}}$ reduction leaving the active site vacant for occupation of another water molecule (new O5) to restart the cycle.

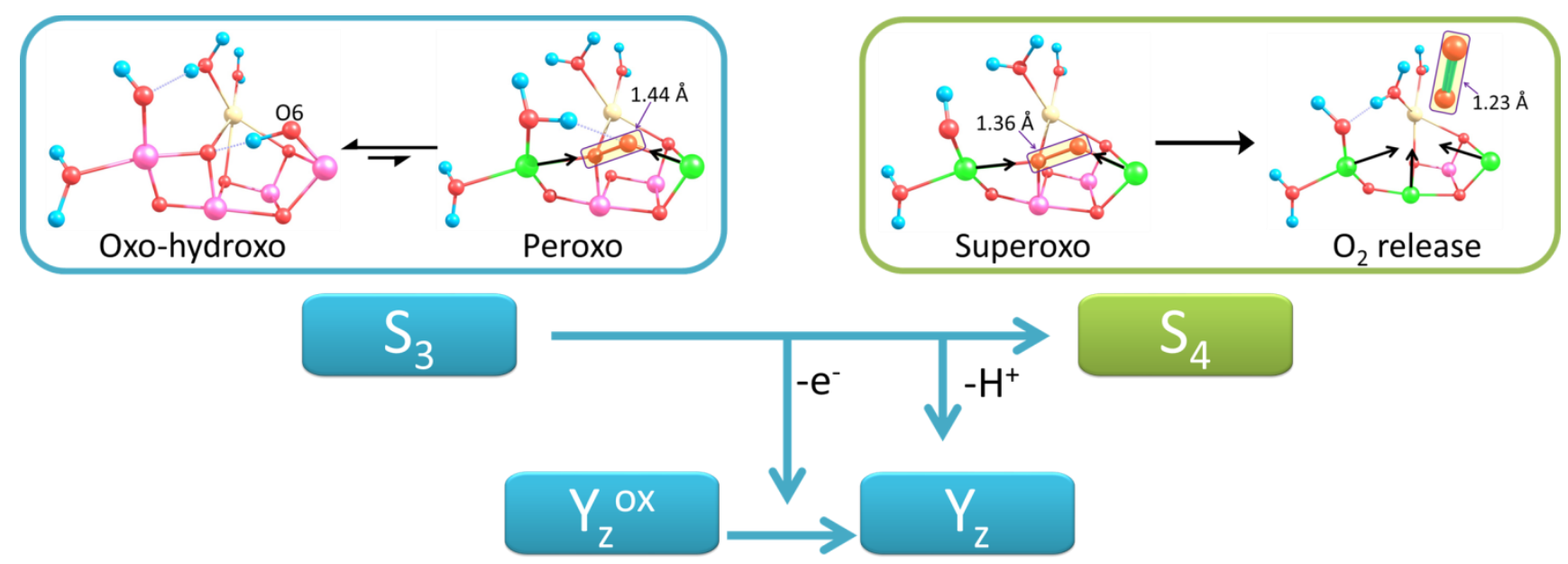

Figure 3: Proposed final intermediates in water oxidation cycle where oxidation only of the peroxo form of $\mathrm{S}_{3}$ leads to superoxo formation in $\mathrm{S}_{4}$ with eventual release of $\mathrm{O}_{2}$. Colouring as in Figure 2. The $\mathrm{S}_{4}$ superoxo shown is generated by one-electron oxidation and deprotonation of the $\mathrm{S}_{3}$ peroxo form followed by geometry optimisation. Formation of triplet oxygen leads to movement of the formed $\mathrm{O}_{6}=\mathrm{O}_{5}$ oxygen molecule from the active site. Arrows indicate Jahn-Teller axes for Mn(III). 
Acknowledgements. TAC acknowledges support from the UK BBSRC Doctoral Training Partnership (DTP) program.

Supporting Information Available: Details of calculations performed and models used, calculated exchange couplings for all models, additional data tables plus comparison of model geometries with additional structural studies. XYZ coordinates of models used.

\section{References}

(1) Renger, G. Mechanism of Light Induced Water Splitting in Photosystem II of Oxygen Evolving Photosynthetic Organisms. Biochim. Biophys. Acta - Bioenerg. 2012, 1817, 1164-1176.

(2) Kok, B.; Forbush, B.; McGloin, M. Cooperation of Charges in Photosynthetic $\mathrm{O}_{2}$ Evolution-I. A Linear Four Step Mechanism. Photochem. Photobiol. 1970, 11, 457475 .

(3) Barber, J. 'Photosysten II: The Water Slitting Enzyme of Photosynthesis and the Origin of Oxygen in Our Atmosphere.' Q. Rev. Biophys. 2016, 49, e14.

(4) Suga, M.; Akita, F.; Sugahara, M.; Kubo, M.; Nakajima, Y.; Nakane, T.; Yamashita, K.; Umena, Y.; Nakabayashi, M.; Yamane, T.; et al. Light-Induced Structural Changes and the Site of $\mathrm{O}=\mathrm{O}$ Bond Formation in PSII Caught by XFEL. Nature 2017, 543, $131-135$.

(5) Young, I. D.; Ibrahim, M.; Chatterjee, R.; Gul, S.; Fuller, F. D.; Koroidov, S.; Brewster, A. S.; Tran, R.; Alonso-Mori, R.; Kroll, T.; et al. Structure of Photosystem II and Substrate Binding at Room Temperature. Nature 2016, 540, 453-457.

(6) Cox, N.; Retegan, M.; Neese, F.; Pantazis, D. A.; Boussac, A.; Lubitz, W. Electronic Structure of the Oxygen-Evolving Complex in Photosystem II Prior to O-O Bond Formation. Science 2014, 345, 804-808.

(7) Krewald, V.; Retegan, M.; Cox, N.; Messinger, J.; Lubitz, W.; DeBeer, S.; Neese, F.; Pantazis, D. A. Metal Oxidation States in Biological Water Splitting. Chem. Sci. 2015, $6,1676-1695$.

(8) Beal, N. J.; Corry, T. A.; O’Malley, P. J. A Comparison of Experimental and Broken Symmetry Density Functional Theory (BS-DFT) Calculated Electron Paramagnetic Resonance (EPR) Parameters for Intermediates Involved in the $\mathrm{S}_{2}$ to $\mathrm{S}_{3}$ State Transition of Nature's Oxygen Evolving Complex . J. Phys. Chem. B 2018, 122, 1394-1407.

(9) Kato, Y.; Akita, F.; Nakajima, Y.; Suga, M.; Umena, Y.; Shen, J.-R.; Noguchi, T. Fourier Transform Infrared Analysis of the S-State Cycle of Water Oxidation in the Microcrystals of Photosystem II. J. Phys. Chem. Lett. 2018, 9, 2121-2126.

(10) Wang, J.; Askerka, M.; Brudvig, G. W.; Batista, V. S. Insights into Photosystem II 
from Isomorphous Difference Fourier Maps of Femtosecond X-Ray Diffraction Data and Quantum Mechanics/Molecular Mechanics Structural Models. ACS Energy Lett. 2017, 2, 397-407.

(11) Ames, W.; Pantazis, D. A.; Krewald, V.; Cox, N.; Messinger, J.; Lubitz, W.; Neese, F. Theoretical Evaluation of Structural Models of the $\mathrm{S}_{2}$ State in the Oxygen Evolving Complex of Photosystem II: Protonation States and Magnetic Interactions. J. Am. Chem. Soc. 2011, 133, 19743-19757.

(12) Beal, N. J.; Corry, T. A.; O’Malley, P. J. Comparison between Experimental and Broken Symmetry Density Functional Theory (BS-DFT) Calculated Electron Paramagnetic Resonance (EPR) Parameters of the $S_{2}$ State of the Oxygen-Evolving Complex of Photosystem II in Its Native (Calcium) and Strontium-Substituted Forms. J. Phys. Chem. B 2017, 121, 11273-11283.

(13) Sanakis, Y.; Sarrou, J.; Zahariou, G.; Petrouleas, V. Q-Band Electron Paramagnetic Resonance Studies of the $\mathrm{S}_{3}$ State of the OEC of Photosystem II. In Photosynthesis. Energy from the Sun: 14th International Congress on Photosynthesis; Allen, J.F. Gantt , E. Golbeck, J.H. Osmond, B., Ed.; Springer, 2008; pp 479-482.

(14) Boussac, A.; Sugiura, M.; Rutherford, A. W.; Dorlet, P. Complete EPR Spectrum of the $\mathrm{S}_{3}$-State of the Oxygen-Evolving Photosystem II. J. Am. Chem. Soc. 2009, 131, 5050-5051.

(15) Boussac, A.; Rutherford, A. W.; Sugiura, M. Electron Transfer Pathways from the $S_{2^{-}}$ States to the $\mathrm{S}_{3}$-States Either after a $\mathrm{Ca}^{2+} / \mathrm{Sr}^{2+}$ or a $\mathrm{Cl}^{-} / \mathrm{I}^{-}$Exchange in Photosystem II from Thermosynechococcus Elongatus. BBA - Bioenerg. 2015, 1847, 576-586.

(16) Sanakis, Y.; Ioannidis, N.; Sioros, G.; Petrouleas, V. A Novel S = 7/2 Configuration of the Mn Cluster of Photosystem II. J. Am. Chem. Soc. 2001, 123, 10766-10767.

(17) Orio, M.; Pantazis, D. A.; Petrenko, T.; Neese, F. Magnetic and Spectroscopic Properties of Mixed Valence Manganese(III,IV) Dimers: A Systematic Study Using Broken Symmetry Density Functional Theory. Inorg. Chem. 2009, 48, 7251-7260.

(18) Retegan, M.; Krewald, V.; Mamedov, F.; Neese, F.; Lubitz, W.; Cox, N.; Pantazis, D. A. A Five-Coordinate Mn(IV) Intermediate in Biological Water Oxidation: Spectroscopic Signature and a Pivot Mechanism for Water Binding. Chem. Sci. 2016, 7, 72-84.

(19) Havelius, K. G. V.; Su, J. H.; Han, G.; Mamedov, F.; Ho, F. M.; Styring, S. The Formation of the Split EPR Signal from the $S_{3}$ State of Photosystem II Does Not Involve Primary Charge Separation. Biochim. Biophys. Acta - Bioenerg. 2011, 1807, $11-21$.

(20) Koulougliotis, D.; Shen, J. R.; Ioannidis, N.; Petrouleas, V. Near-IR Irradiation of the $\mathrm{S}_{2}$ state of the Water Oxidizing Complex of Photosystem II at Liquid Helium Temperatures Produces the Metalloradical Intermediate Attributed to $\mathrm{S}_{1} \mathrm{Y}_{\mathrm{Z}}$. Biochemistry 2003, 42, 3045-3053.

(21) Hagen, W. R. Biomolecular EPR Spectroscopy; CRC Press: Boca Raton, USA, 2009.

(22) Sathiya, M.; Rousse, G.; Ramesha, K.; Laisa, C. P.; Vezin, H.; Sougrati, M. T.; 
Doublet, M. L.; Foix, D.; Gonbeau, D.; Walker, W.; et al. Reversible Anionic Redox Chemistry in High-Capacity Layered-Oxide Electrodes. Nat. Mater. 2013, 12, 827835.

(23) Renger, G. Water Cleavage by Solar Radiation- an Inspiring Challenge of Photosynthesis Research. Photosynth. Res. 1993, 38, 229-247.

(24) Isobe, H.; Shoji, M.; Shen, J.-R.; Yamaguchi, K. Chemical Equilibrium Models for the $\mathrm{S}_{3}$ State of the Oxygen-Evolving Complex of Photosystem II. Inorg. Chem. 2016, 55, $502-511$.

(25) Pushkar, Y.; Davis, K. M.; Palenik, M. C. Model of the Oxygen Evolving Complex Which Is Highly Predisposed to O-O Bond Formation. J. Phys. Chem. Lett. 2018, 9, 3525-3531.

(26) Pantazis, D. A. Missing Pieces in the Puzzle of Biological Water Oxidation. ACS Catal. 2018, 8, 9477-9507.

(27) Halfen, J. A.; Mahapatra, S.; Wilkinson, E. C.; Kaderli, S.; Young, V. G.; Que, L.; Zuberbühler, A. D.; Tolman, W. B. Reversible Cleavage and Formation of the Dioxygen O-O Bond within a Dicopper Complex. Science. 1996, 271, 1397-1400.

(28) Elwell, C. E.; Gagnon, N. L.; Neisen, B. D.; Dhar, D.; Spaeth, A. D.; Yee, G. M.; Tolman, W. B. Copper-Oxygen Complexes Revisited: Structures, Spectroscopy, and Reactivity. Chem. Rev. 2017, 117, 2059-2107.

(29) Glöckner, C.; Kern, J.; Broser, M.; Zouni, A.; Yachandra, V. K.; Yano, J. Structural Changes of the Oxygen-Evolving Complex in Photosystem II during the Catalytic Cycle. J. Biol. Chem. 2013, 288, 22607-22620.

(30) Yano, J.; Yachandra, V. K. Oxidation State Changes of the $\mathrm{Mn}_{4} \mathrm{Ca}$ Cluster in Photosystem II. Photosynth. Res. 2007, 92, 289-303.

(31) Messinger, J.; Robblee, J. H.; Bergmann, U.; Fernandez, C.; Glatzel, P.; Visser, H.; Cinco, R. M.; McFarlane, K. L.; Bellacchio, E.; Pizarro, S. A.; et al. Absence of MnCentered Oxidation in the $\mathrm{S}_{2} \rightarrow \mathrm{S}_{3}$ Transition: Implications for the Mechanism of Photosynthetic Water Oxidation. J. Am. Chem. Soc. 2001, 123, 7804-7820.

(32) Yano, J.; Yachandra, V. $\mathrm{Mn}_{4} \mathrm{Ca}$ Cluster in Photosynthesis: Where and How Water Is Oxidized to Dioxygen. Chem. Rev. 2014, 114, 4175-4205.

(33) Zaharieva, I.; Chernev, P.; Berggren, G.; Anderlund, M.; Styring, S.; Dau, H.; Haumann, M. Room-Temperature Energy-Sampling K $\beta$ X-Ray Emission Spectroscopy of the $\mathrm{Mn}_{4} \mathrm{Ca}$ Complex of Photosynthesis Reveals Three ManganeseCentered Oxidation Steps and Suggests a Coordination Change Prior to $\mathrm{O}_{2}$ Formation. Biochemistry 2016, 55,4197-4211.

(34) Schuth, N.; Zaharieva, I.; Chernev, P.; Berggren, G.; Anderlund, M.; Styring, S.; Dau, H.; Haumann, M. Ka X-Ray Emission Spectroscopy on the Photosynthetic OxygenEvolving Complex Supports Manganese Oxidation and Water Binding in the $\mathrm{S}_{3}$ State. Inorg. Chem. 2018, 57, 10424-10430.

(35) Dau, H.; Haumann, M. Eight Steps Preceding O-O Bond Formation in Oxygenic Photosynthesis- A Basic Reaction Cycle of the Photosystem II Manganese Complex. 
Biochim. Biophys. Acta 2007, 1767, 472-483.

(36) Nilsson, H.; Rappaport, F.; Boussac, A.; Messinger, J. Substrate-water Exchange in Photosystem II Is Arrested before Dioxygen Formation. Nat. Commun. 2014, 5, 4305.

(37) McEvoy, J. P.; Brudvig, G. W. Water-Splitting Chemistry of Photosystem II. Chem. Rev. 2006, 106, 4455-4483.

(38) Askerka, M.; Brudvig, G. W.; Batista, V. S. The $\mathrm{O}_{2}$-Evolving Complex of Photosystem II: Recent Insights from Quantum Mechanics/Molecular Mechanics (QM/MM), Extended X-Ray Absorption Fine Structure (EXAFS), and Femtosecond X-Ray Crystallography Data. Acc. Chem. Res. 2017, 50, 41-48.

(39) Siegbahn, P. E. M. Water Oxidation Mechanism in Photosystem II, Including Oxidations, Proton Release Pathways, O-O Bond Formation and $\mathrm{O}_{2}$ Release. Biochim. Biophys. Acta - Bioenerg. 2013, 1827, 1003-1019.

(40) Siegbahn, P. E. M. O-O Bond Formation in the $\mathrm{S}_{4}$ State of the Oxygen-Evolving Complex in Photosystem II. Chem. - A Eur. J. 2006, 12, 9217-9227.

(41) Babcock, G. T.; Blankenship, R. E.; Sauer, K. Reaction Kinetics for Positive Charge Accumulation on the Water Side of Choloplast Photosystem II. FEBS Lett. 1976, 61, 286-289.

(42) Armstrong, F. A. Why Did Nature Choose Manganese to Make Oxygen? Philos. Trans. R. Soc. B Biol. Sci. 2008, 363, 1263-1270.

(43) Jensen, S. C.; Davis, K. M.; Sullivan, B.; Hartzler, D. A.; Seidler, G. T.; Casa, D. M.; Kasman, E.; Colmer, H. E.; Massie, A. A.; Jackson, T. A.; et al. X-Ray Emission Spectroscopy of Biomimetic Mn Coordination Complexes. J. Phys. Chem. Lett. 2017, $8,2584-2589$.

(44) Koppenol, W. H.; Stanbury, D. M.; Bounds, P. L. Electrode Potentials of Partially Reduced Oxygen Species, from Dioxygen to Water. Free Radic. Biol. Med. 2010, 49, 317-322. 